\title{
The Relationship between Mandibular Position and Sole Pressure
}

\author{
Yoshiyasu Satoh, DDS, PhD, Kazuo Higashi, DDS, PhD, Takahiro Mizumori, DDS, PhD, \\ and Hirofumi Yatani, DDS, PhD \\ Department of Fixed Prosthodontics, Osaka University Graduate School of Dentistry, Osaka, Japan
}

\section{Clinical significance}

This study demonstrates the possibility that the stomatognathic system is involved in the functioning of other body organs.

\begin{abstract}
Purpose: To clarify the effects of deviated mandibular positions on the center of sole pressure in terms of fluctuations and positional changes.

Methods: Of 100 subjects at Osaka University Graduate School of Dentistry, 30 faculty members and students who exhibited no mandibular deviation (i.e., who had a median menton angle and an SNB angle within one standard deviation of the mean) were selected. Using a machine capable of assessing the distribution of sole pressure, the center of sole pressure and the degree of fluctuations in the center of sole pressure corresponding to the mandibular positions, were measured at deviated mandibular positions. The mandible was moved $3 \mathrm{~mm}$ in the left, right, or anterior directions and maximally in the posterior direction. The data were analyzed statistically using a paired $t$ test with a significance level of $P=0.05$.
\end{abstract}

Results: No tendencies were observed between the positional changes in the center of sole pressure and the mandible moving from the intercuspal position. Whereas the degree of fluctuation increased significantly, irrespective of the direction of change, for the subjects in whom the position of the center of sole pressure did not change, or changed in the same direction as the deviated mandibular position, it did not increase for subjects in whom the position of the center of sole pressure changed in the direction opposite to that of the deviated mandibular position.

Conclusion: The results of this study suggest the possibility that deviated mandibular positions do not affect the positional changes in the center of sole pres-

\author{
Corresponding to: Dr Yoshiyasu Satoh \\ Department of Fixed Prosthodontics, Osaka University \\ Graduate School of Dentistry \\ 1-8 Yamada-oka, Suita, Osaka 565-0871, Japan \\ Tel: 81-6-6879-2946, Fax: 81-6-6879-2947 \\ E-mail: yoshisat@dent.osaka-u.ac.jp
}

Received on July 9, 2006 / Accepted on November 16, 2006 sure, but do affect the fluctuations in relation to the direction of positional changes.

Key words: mandibular position, sole pressure, positional change, fluctuation

\section{Introduction}

Mandibular position is determined by various anatomical features, including teeth, the temporomandibular joints, masticatory muscles, and ligaments. ${ }^{1,2}$ Deviation in mandibular position can disrupt the functions of these features, thus resulting in stomatognathic dysfunction. ${ }^{3-5}$ Some patients with temporomandibular joint disorders have in addition to three major symptomslimitation of mouth opening, joint noises, and masticatory muscle or joint pain-mandibular deviation and/or poor body posture. ${ }^{6-9}$ Several studies have reported that splint therapy in such patients simultaneously alters mandibular position and body posture, thus suggesting a possible relationship between mandibular position and body posture. ${ }^{10-12}$ The relationship between stomatognathic and body functions has been previously examined. ${ }^{13,14}$ These studies have assessed changes in body functions, objectively and quantitatively, using the fluctuations in the center of sole pressure as an index. While some studies have reported that vertical or horizontal deviations in mandibular position caused fluctuations in the center of sole pressure, others have not. Consequently, there is no general consensus on the relationship between mandibular position and the center of sole pressure. ${ }^{15-20}$ The objective of the present study was to clarify the effects of deviated mandibular positions on the center of sole pressure by referring to an index of body positional changes, in addition to that for fluctuations. We hypothesized that the deviation of mandibular position would lead to positional changes and fluctuations in the center of sole pressure. 


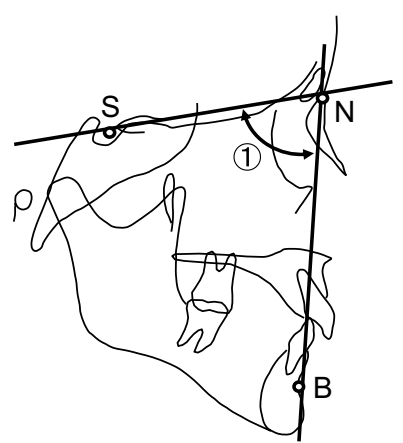

(1) $\angle$ SNB

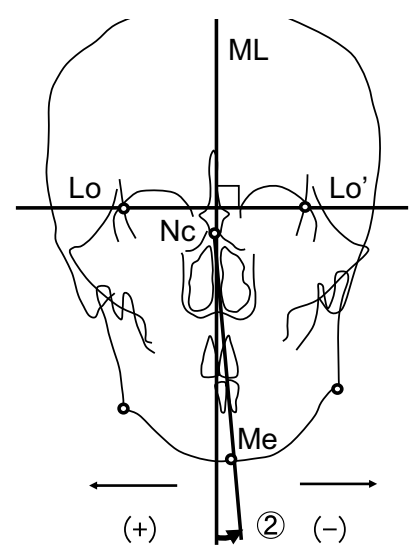

(2) the median menton angle
Fig. 1 Mandibular positions in cephalogram. S: Sella, N: Nasion, B: Point B, ML: Mid Line, Lo: Right Latero-orbitale, Lo': Left Latero-orbitale, Nc: Crista galli, Me: Menton.

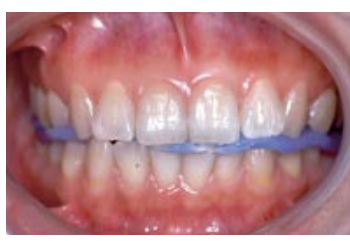

right deviated position

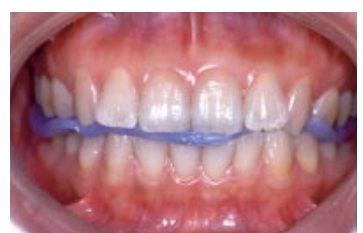

left deviated position

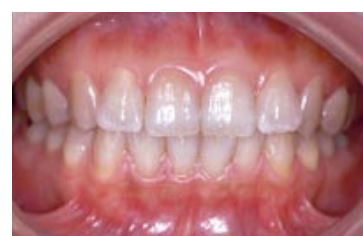

Intercuspal position

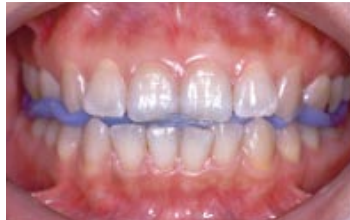

anteriorly deviated position

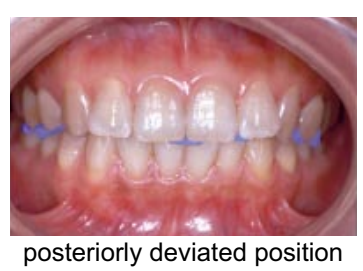

posteriorly deviated position
Fig. 2 Mandibular positions at recordings.

\section{Materials and methods}

\section{Subjects}

A total of 100 faculty members and students at Osaka University Graduate School of Dentistry, who met the following criteria, were selected and agreed to participate in this study: no subjective or objective stomatognathic abnormality (i.e., people with normal occlusion); no missing teeth, except for the third molar; had not undergone orthodontic therapy; and had no past history of trunk or extremity fracture or disease that affects balance function. In order to exclude those with mandibular deviation, all subjects were

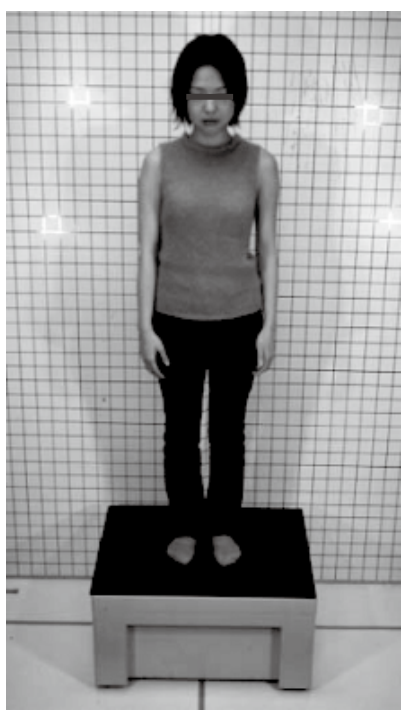

Fig. 3 Measurement device and standing posture.

measured for the distribution of sole pressure; 30 subjects with a median menton angle and an SNB angle within one standard deviation of the mean were included (Fig. 1).

\section{Measurement device}

A machine capable of assessing the distribution of sole pressure (Body Balance Measuring System; Nihon Light Service, Japan) was used. This machine records the distribution of weight per unit area. A load applied to each unit area, which is $5-\mathrm{mm}$ square, is recorded. Using software included in the system, weight ratios for any given area can be calculated.

\section{Mandibular position}

With the incisal point in the intercuspal position as the reference point, the mandible was moved 3 $\mathrm{mm}$ in the left, right, or anterior directions, and maximally in the posterior direction. Each deviated mandibular position was maintained using a plastic positioning device. In these four mandibular positions, and also in the intercuspal position, the distribution of sole pressure was measured with the Body Balance Measuring System. The measurements were repeated three times, and mean of three records was calculated (Fig. 2).

\section{Recording and setting}

During each measurement, each subject was instructed to stand naturally, looking straight at a mirror that was placed $1 \mathrm{~m}$ in front of them, and to lightly maintain the intercuspal position (Fig. 3 ). The subjects were then instructed to close 


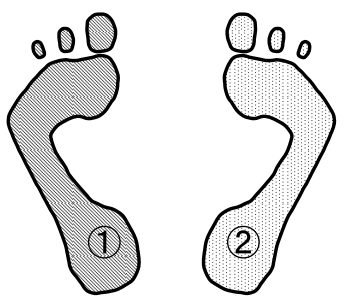

A. left and right areas

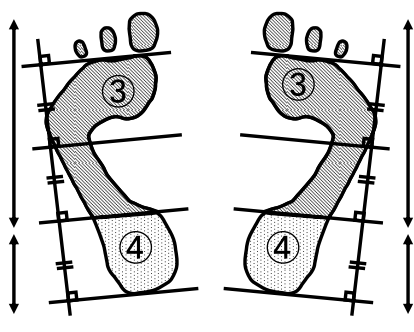

B. anterior and posterior areas

Fig. 4 Sole pressure distribution. (1): left area, (2): right area, (3): anterior area, (4): posterior area.
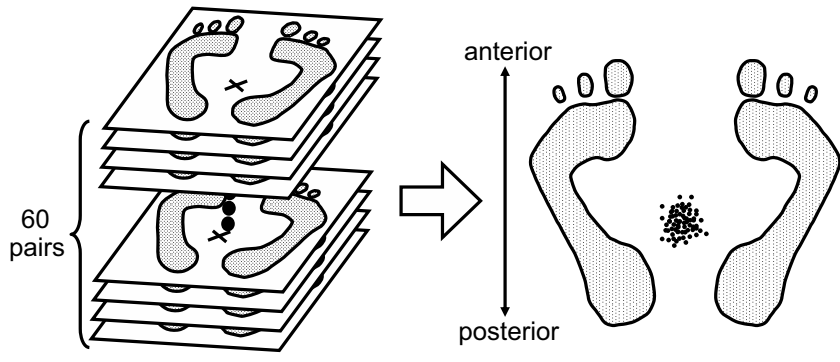

left right

Fig. 5 The position and the degree of fluctuation of the center of sole pressure.

their eyes, and after 20 seconds sampling was carried out at a frequency of $2 \mathrm{~Hz}$ for 30 seconds. Sole pressure distribution was divided in two directions: the left and right areas (left and right feet); and anterior and posterior areas (excluding the toes, each foot was divided into two areas by drawing a line at the anterior two thirds of the foot). ${ }^{26}$ Using the following formula, the weight ratio in the left and right areas and the anterior and posterior areas was determined (Fig. 4).

The weight ratio in the left and right areas $(\%)=\{((2)-(1)) /(1)+(2))\} \times 100$

The weight ratio in the anterior and posterior areas $(\%)=\{(3-(4)) /(3)+(4))\} \times 100$

The mean of a total of 60 pairs of sole pressure ratios (frequency of $2 \mathrm{~Hz}$ for 30 seconds) obtained in each test was defined as the center of sole pressure, and the standard deviation represented the degree of fluctuation in the center of sole pressure (Fig. 5).

\section{Investigated items and methods}

In relation to the positional changes and fluctuations in the center of sole pressure in the intercuspal position, the amount and direction of changes in the center of sole pressure in each deviated position were determined. In the present study, changes in the center of sole pressure were

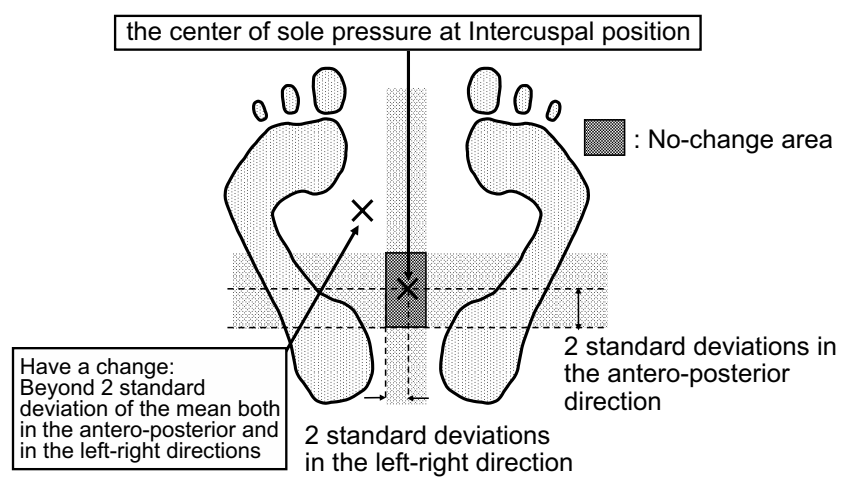

Fig. 6 Decision of the change of the center of sole pressure.

defined as changes greater than two standard deviations of the mean for the 100 subjects. Based on this assessment criterion, the 30 subjects were divided into three groups, each with respect to changes in the center of sole pressure in the left-right direction (change to the left, no change, and change to the right) and in the antero-posterior direction (change in the anterior direction, no change, and change in the posterior direction) (Fig. 6).

\section{Statistical analysis}

The difference between the center of sole pressure in each group before and after the change of mandibular position was analyzed using a paired Student's t test. A chi-square test was used to examine whether there were any tendencies in the changes of the center of sole pressure induced by moving the mandible from the intercuspal position. For these comparisons, a probability level of $P<0.05$ was considered statistically significant.

\section{Results}

When the mandible was moved to the left, there was a change in the center of sole pressure to the left in 14 subjects, to the right in 12 subjects, and no change in 4 subjects (Fig. 7). Similarly, when the mandible was moved to the right, there was a change in the center of sole pressure to the right in 16 subjects, to the left in 9 subjects, and no change in 5 subjects (Fig. 7). When the mandible was moved in the anterior direction, there was a change in the center of sole pressure in the anterior direction in 5 subjects, in the posterior direction in 16 subjects, and no change in 9 sub- $^{-}$ jects (Fig. 8). When the mandible was moved in 

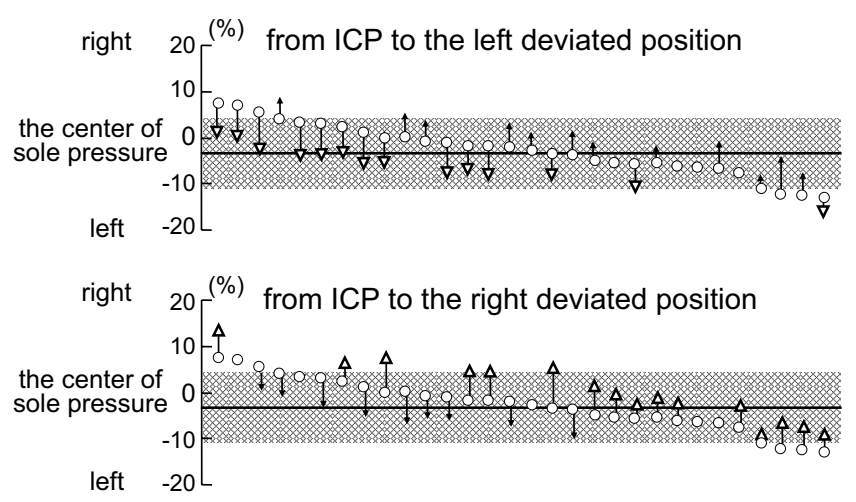

Fig. 7 The left-right directional changes of the center of sole pressure when the mandible deviated from the intercuspal position (ICP) to the left or right jaw position. Each circle ( 0 ) denotes the center of sole pressure of each subject in the ICP (weight ratio). Each arrow denotes the amount and direction of the weight ratio changes when the subject's mandible deviated from the ICP to the left or right jaw position.

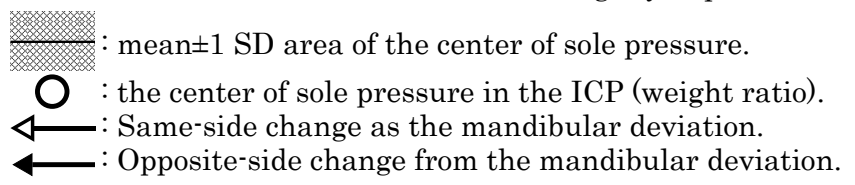
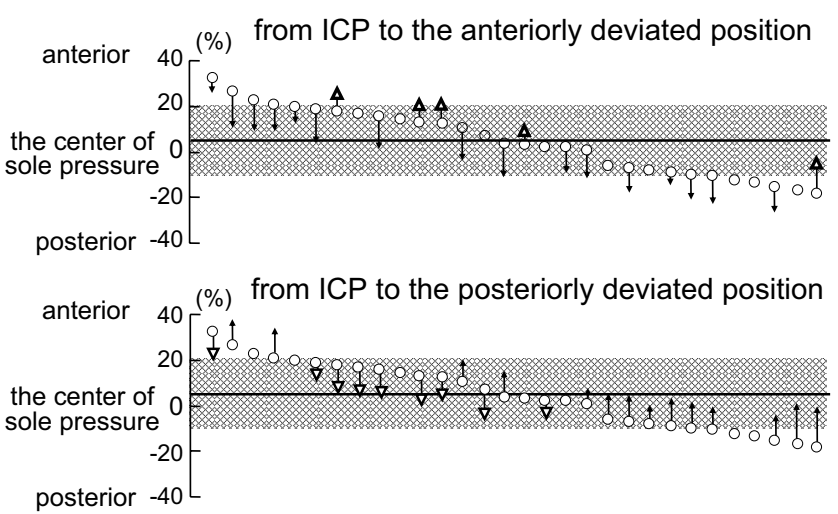

Fig. 8 The antero-posterior directional changes of the center of sole pressure when the mandible deviated from the intercuspal position (ICP) to the anterior or posterior jaw position. Each circle ( $\mathbf{O}$ ) denotes the center of sole pressure of each subject in the intercuspal position (weight ratio). Each arrow denotes the amount and direction of the weight ratio changes when the subject's mandible deviated from the ICP to the anterior or posterior jaw position.

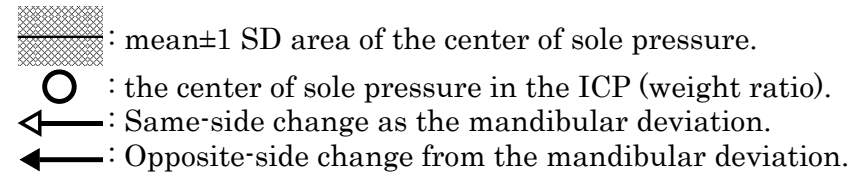

Table 1 Relationship between the changes and the degree of fluctuation of the center of sole pressure.

\begin{tabular}{|c|c|c|c|c|}
\hline \multirow{2}{*}{$\begin{array}{l}\text { The changes of the } \\
\text { center of } \\
\text { sole pressure }\end{array}$} & \multicolumn{4}{|c|}{ change of mandibular position } \\
\hline & $\begin{array}{c}\text { Left } \\
\text { deviated position }\end{array}$ & $\begin{array}{c}\text { Right } \\
\text { deviated position }\end{array}$ & $\begin{array}{c}\text { Anteriorly } \\
\text { deviated position }\end{array}$ & $\begin{array}{c}\text { Posteriorly } \\
\text { deviated position }\end{array}$ \\
\hline $\begin{array}{l}\text { Same-side change } \\
\text { group }\end{array}$ & $\begin{array}{c}\left.\frac{1.45 \pm 0.18}{2.48 \pm 0.18}\right] * \\
(\mathrm{n}=14)\end{array}$ & $\begin{array}{c}\left.\frac{1.45 \pm 0.15}{2.38 \pm 0.16}\right] * \\
(\mathrm{n}=16)\end{array}$ & $\begin{array}{c}5.23 \pm 0.61 \\
6.75 \pm 0.25 \\
\quad(n=5)\end{array}$ & $\begin{array}{c}\frac{4.80 \pm 0.56}{6.52 \pm 0.20} \\
\quad(n=9)\end{array}$ \\
\hline $\begin{array}{l}\text { No-change } \\
\text { group }\end{array}$ & 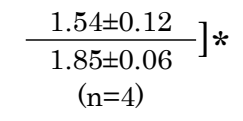 & $\begin{array}{c}\left.\frac{1.32 \pm 0.33}{1.85 \pm 0.14}\right] * \\
(\mathrm{n}=5)\end{array}$ & $\begin{array}{c}\left.\frac{4.77 \pm 0.34}{5.87 \pm 0.59}\right] * \\
\quad(\mathrm{n}=9)\end{array}$ & $\begin{array}{c}\frac{4.95 \pm 0.54}{5.99 \pm 0.58} \\
(\mathrm{n}=7)\end{array}$ \\
\hline \multirow{2}{*}{$\begin{array}{l}\text { Opposite-side change } \\
\text { group }\end{array}$} & $1.38 \pm 0.24$ & $1.46 \pm 0.21$ & $4.94 \pm 0.68$ & $5.02 \pm 0.66$ \\
\hline & $\begin{array}{c}1.40 \pm 0.21 \\
(\mathrm{n}=12)\end{array}$ & $\begin{array}{c}1.52 \pm 0.20 \\
(\mathrm{n}=9)\end{array}$ & $\begin{array}{c}5.00 \pm 0.71 \\
(\mathrm{n}=16)\end{array}$ & $\begin{array}{c}5.12 \pm 0.57 \\
(\mathrm{n}=14) \quad(\%)\end{array}$ \\
\hline
\end{tabular}

the posterior direction, there was a change in the center of sole pressure in the posterior direction in 9 subjects, in the anterior direction in 14 sub- $^{-}$ jects, and no change in 7 subjects (Fig. 8).

Therefore, no tendencies were observed in the positional changes in the center of sole pressure induced by moving the mandible from the intercuspal position $\left(\chi^{2}\right.$ test; $\left.P=0.08\right)$. Furthermore, the degree of fluctuation increased significantly, irrespective of the direction of change, for the subjects in whom the position of the center of sole pressure changed in the same direction as the deviated mandibular position, and did not change in comparison with the subjects in whom the position of the center of sole pressure changed in the opposite direction $(P<0.05)$. There was no significant change in the degree of fluctuation for the subjects in whom the position of the center of sole pressure changed in the opposite direction to the deviated mandibular position (Table 1). 


\section{Discussion}

In general, fluctuations in the center of sole pressure are analyzed to objectively assess the body's balance function. Studies have been conducted that have changed mandibular positions, ${ }^{16}$ occlusal heights ${ }^{17}$ or occlusal support areas ${ }^{20}$ and that have examined patients with temporomandibular joint disorders before and after therapy. ${ }^{18}$ Fluc- $^{-}$ tuations in the center of sole pressure are an index of the body's stability; however, they may not represent changes in body posture. Hence, the present study focused on the positional changes in the center of sole pressure due to postural changes in an attempt to clarify the effects of different mandibular positions on the center of sole pressure.

In order to measure the fluctuations and positional changes in the center of sole pressure, subjects with diseases that induce organic changes in the body, such as rheumatoid arthritis, or with a past history of trunk or extremity fracture, were excluded. ${ }^{21}$ Further, people with a past history of diseases related to balance function, such as vertigo, were also excluded because it would have been difficult to assess fluctuations in the center of sole pressure. Furthermore, since stomatognathic dysfunction may affect balance and posture maintenance, people with normal occlusion who did not have subjective or objective stomatognathic dysfunction were enrolled..$^{22,23}$

In the present study, the subjects were instructed to close their eyes during the test. Visual input is involved in the maintenance of standing posture, and the degree of body fluctuation is greater when the eyes are closed than when they are open. In the present study, in order to eliminate visual compensation effects, such as visual standing reflex, and accurately capture the changes in the center of sole pressure induced by deviated mandibular positions, the test was conducted with the subjects' eyes closed.

Whenever possible, the center of sole pressure was measured according to the standards for a center of gravity test established by the Japanese Society of Balance Neurology. The test was conducted in Broca's natural head position, ${ }^{24,25}$ which is considered a highly reproducible posture.

The center of sole pressure always fluctuates in order to maintain itself at a certain point. Further, posture is stable when fluctuations in the center of sole pressure are minimal. Therefore, fluctuations and positional changes in the center of sole pressure should be analyzed together. In the present study, postural stability was maintained without an increase in fluctuations in the center of sole pressure for the subjects in whom the position of the center of sole pressure changed in the opposite direction to the deviated mandibular position. In addition, in the subjects with no positional change in the center of sole pressure, and those in whom the position of the center of sole pressure changed in the same direction as the deviated mandibular position, the fluctuations in the center of sole pressure increased, thus lowering postural stability. These findings might suggest that when maintaining postural stability in response to deviated mandibular position, it is necessary to change the position of the center of sole pressure in the opposite direction to the deviated mandibular position. However, no set tendencies were observed for the positional changes in the center of sole pressure with respect to deviated mandibular positions. The reason for this may be that deviated mandibular positions do not directly affect the center of sole pressure, and that there are individual differences in the responses to transient deviated mandibular positions.

\section{Conclusion}

The results of the present study suggest that deviated mandibular positions do not affect the positional changes in the center of sole pressure but do affect the fluctuations in relation to the direction of positional changes, and that the stomatognathic system is involved in the functioning of other body organs.

\section{References}

1. Kawamura Y. Oral Physiology. 158-232, Kyoto: Nagasuesyoten Inc., 1972. (in Japanese)

2. Hasegawa H, Bandou E. Clinical Occlusion Encyclopedia. 279-317, Tokyo: Ishiyaku Publishers Inc., 1997. (in Japanese)

3. Shore NA. Temporomandibular Joint Dysfunction and Occlusion Equilibration. 2nd ed: J. B. Lippincott Co.: 133-143, 1976.

4. Weinberg NA. Role of condylar position in TMJ dysfunction pain syndrome. J Prosthet Dent 41: 636-643, 1976.

5. MacConkey D. The relationship of posture and dental health. J Orofacial Myology 17: 8-10, 1991. 
6. Kelly H. Vertigo attributable to dental and temporomandibular joint causes. J Prosthet Dent 14: 159-173, 1984.

7. Schokker R. The result of treatment of the masticatory system of chronic headache patients. J Craniomandib Disord 4: 126-130, 1990.

8. Lee WY. The relationship between forward head posture and temporomandibular disorders. J Orofacial Pain 9: 161-167, 1995.

9. Miyajima T, Kai S, Kai H et al. Clinical observation about the related symptom in the temporomandibular disorders. J Jpn Soc TMD 4: 107-121, 1992. (in Japanese)

10. MacConkey D. The relationship of posture and dental health. J Orofacial Myology 17: 8-10, 1991.

11. Wada K. Occlusion and posture. Aca Gnath Occlu 23:158-164, 2003. (in Japanese)

12. Yamamura F, Shimazaki N, Yamamori T. A case which judged improvement of the constitutional symptom by simple psychotherapy and occlusal reorganization. Ohu Dent J 25: 103-108, 1998. (in Japanese)

13. Kobayashi Y, Mastumoto T, Ishigami K et al. Relation with the occlusion and the body functions. J Jpn Prosthodont Soc 40: 1-23, 1996.

14. Kouno M, Tsuchida Y. Concerning of the Occlusion and the body. Shikaitenbou, 903-917, Tokyo: Ishiyaku Publishers Inc., 1996. (in Japanese)

15. Miyata T. Study about the relation between the state of the stomatognathic system and the general condition I-1. J Jpn Prosthodont Soc 32: 1233-1240, 1988.

16. Shimada J. Study about the relation between the state of the stomatognathic system and the general condition-The influence exerted on the degree of fluctuations in the center of sole pressure at horizon way-. J Jpn Prosthodont Soc 35: 501-514, 1991.

17. Satoh T. Study about the relation between the state of the stomatognathic system and the general condition. - The influence exerted on the degree of fluctuations in the center of sole pressure at vertical way-. J Jpn Prosthodont Soc 35: 574-584, 1991.

18. Shimada J. Study about the relation between the state of the stomatognathic system and the general condition-A change of the degree of fluctuations in the center of sole pressure before and after treatment at the TMD-Patients-. J Jpn Soc TMD 4: 79-92, 1992. (in Japanese)

19. Ferrario VF, Sforza C, Schmitz JH et al. Occlusion and center of foot pressure variation: is there a relationship? J Prosthet Dent 76: 302-308, 1996.

20. Yoshino G. Changes in weight distribution at the feet due to occlusal supporting zone loss during clenching. Cranio 21: 279-278, 2003.

21. Miyamoto M, Shirai Y. Foot-deformation of a chronic rheumatism-Focusing on an analysis of the foot pressure-. J Bone Joint Ligament 3: 1355-1363, 1990. (in Japanese)

22. Tokita H. Body-balance_-in balance physiology-. JOHNS 14: 763-769, 1998. (in Japanese)

23. Yagi S. Physiological knowledge necessary to medical examination and treatment of dizziness. Modern Physician 9: 409-413, 1989. (in Japanese)

24. Sakaguchi M, Taguchi K, Iijima N et al. The degree of fluctuations in the center of sole pressure and head at the end vestibular disturbance patient and the centrally-acting imbalance patient. J Clinic Otolaryn 100: 7-14, 1999. (in Japanese)

25. Ciancaglini R, Colombo-Bolla G, Gherlone EF et al. Orientation of craniofacial planes and temporomandibular disorder in young adults with normal occlusion. J Oral Rehabil 30: 878-886, 2003.

26. Niitu Y. Measurement of Tactile Pressure Distribution by Pressure-Optical Conversion. IM 95-53: 47-51, 1995. (in Japanese) 